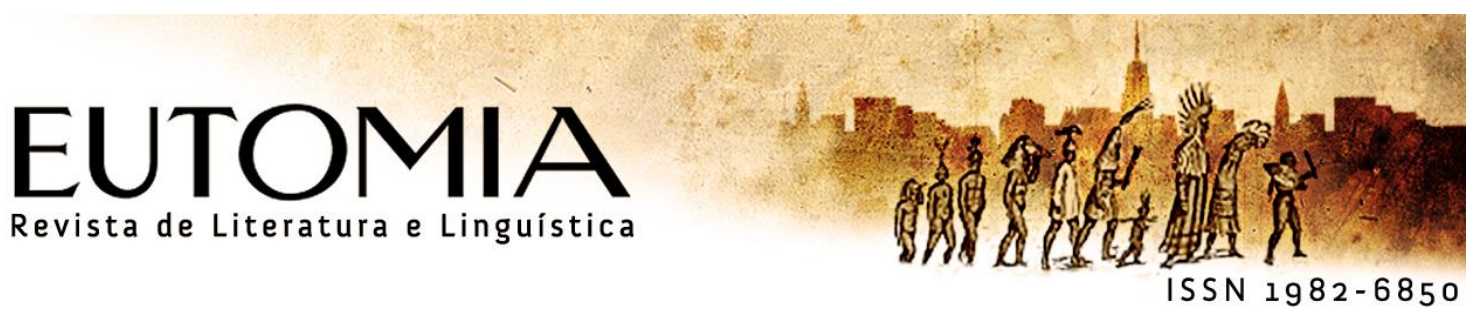

\title{
Tras cuernos, palos
}

\author{
Román García Arrospidei (Universidad de la República, Uruguay)
}

\begin{abstract}
Resumen: El texto no pretende examinar "Los cuernos de Don Friolera" como un especialista literario, sino como un mero lector curioso; Ramón Del Valle Inclán, 1869-1936, inserta "Los cuernos de Don Friolera" en una serie que llama "esperpentos". Él se ríe de la realidad y se la presenta al lector-espectador a través de una lente que la deforma y, que a pesar de lo trágico que muestra, la hace parecer cómica. Para Alardis (2016) el esperpento descoyunta, si es que puede decirse así, la realidad; trastorna por completo la imagen aparente que tenemos de su estructura y de su dinámica, precisamente para mejor mostrarnos cómo son, cómo es la realidad. Creemos ver en este «descoyuntamiento» de la realidad una finalidad muy semejante a la que Brecht buscaba con su idea del «distanciamiento». Sin embargo, el fin último que propone Brecht es la desalienación. En los esperpentos, el método es más elaborado y más directo. Es importante destacar que en toda la obra incluidos introducción y epílogo, sobrevuela la presencia militar en España. El texto en sí, dividido en tres partes, contiene su propia proyección de sombras. En la primera los dos intelectuales discuten sobre el arte y su sentido en cuanto contemplan en un teatro de muñecos un adelanto más tosco de lo que veremos en la segunda parte. Cada una de las escenas se inicia con una descripción por el estilo, esto sin contar con la de los personajes. El lenguaje utilizado por el autor refuerza esta idea exagerada, deforme, fantochesco. El drama central proyecta su sombra sobre el epílogo: un ciego recita la historia. Valle mediante un juego de espejos caricaturiza la realidad de España de los años veinte del siglo pasado sin olvidar ningún elemento importante: los militares y su concepto del honor, la guerra de Marruecos, los separatismos reprimidos y el atraso con respecto a otros países europeos. El matador es honrado por el Rey y su retrato aparece en las Revistas Ilustradas.

Palabras clave: Valle-Inclán; Cuernos de Don Friolera; Brecht; Esperpento.
\end{abstract}

Abstract: The text do not intend to examine "The Horns of Don Friolera" as a literary specialist, but as a mere curious reader. Ramón Del Valle Inclán, 1869-1936, insert, "The horns of Don Friolera" in a series called "esperpentos". He laughs at reality and presents it to the reader-spectator through a lens that deforms it and, despite the tragedy that it shows, 
makes it seem comical. Alardis (2016) defend the esperpento disjointed, if it can be said that way, the reality; completely disrupts the apparent image we have of its structure and its dynamics, precisely to better show us how they are, how is reality. We believe that in this "dis-council" of reality there is a purpose very similar to that Brecht searched with his idea of "distancing. However, the ultimate goal proposed by Brecht is the misalignment. In the esperpentos, the method is more elaborate and more direct. It is worth highlighting that throughout the work, including introduction and epilogue, the military presence in Spain overflies. Valle evades from an improvised government that keeps Spain in an almost medieval backwardness. The text itself, divided into three parts, contains its own projection of shadows. In the first two, intellectuals discuss art and its meaning while contemplating in a puppet theater a rough preview of what we will see in the second part. Each of the scenes starts with a description like that, without counting the characters. The language used by the author reinforces the exaggerated, deformed and marionettes idea. The central drama casts its shadow on the epilogue: a blind man recites the story. The King honors the killer and his portrait appears in the Illustrated Journals. In summary, Valle through a game of mirrors caricatures the reality of Spain in the twenties of the last century without forgetting any important element: the military and its concept of honor, the Moroccan war, repressed separatisms and backwardness with respect to others European countries.

Keywords: Valle-Inclán; Cuernos de Don Friolera; Brecht; Spanish Grotesque.

La corriente consumista actual se empeña en dejar el arte en el olvido y los nadadores poco avisados bracean agarrándose de lo inmediato, ignorando las joyas en clave del pasado. Lógico: es más fácil bajar una app que desempolvar "Los cuernos de Don Friolera" que duermen en el estante y adentrarse en el mundo fantasmagórico descrito por Valle Inclán. Sin embargo, ¿ese universo será tan diferente de lo que hoy vivimos? Descúbralo el lector poco perezoso. ¡Suerte!

El oficial pundonoroso, jamás perdona a la esposa adúltera. Es una barbaridad. Para muchos lo es. Yo no lo admito: A la mujer que sale mala, pena capital. El paisano, y el propio oficial retirado, en algunas ocasiones, muy contadas, pueden perdonar: Se dan circunstancias: La mujer que violan contra su voluntad, la que atropellan acostada durmiendo, la mareada con alguna bebida: Solamente en estos casos admito yo la caída de Loreta. Y en estos casos tampoco podría perdonarla. Sirvo en activo. Pudiera hacerlo retirado del servicio. ¡Friolera! (VALLE INCLÁN, 1925, p. 45)

No pretendo examinar "Los cuernos de Don Friolera" como un especialista literario, sino como un mero lector curioso; lector que se pregunta si en los tiempos que corren, con todos los avances tecnológicos, médicos, científicos y morales que los 
medios de comunicación masivos no se cansan de proclamar un día sí y otro también, cabría representar una obra de teatro que muestra como un supuesto cornudo termina por matar a su hija cuando en realidad quería matar a su mujer para borrarse el adorno de la frente.

Esperpentos. Ramón del Valle Inclán, 1869-1936, inserta Los cuernos de Don Friolera en una serie que llama "esperpentos. ¿Qué son estos "esperpentos"? La Real Academia define esta palabra como "Persona, cosa o situación grotescas o estrafalarias." Valle se ríe de la realidad y se la presenta al lector-espectador a través de una lente que la deforma y, que a pesar de lo trágico que muestra, la hace parecer cómica. Según Ricardo Domenech, citado por Arlandis:

El esperpento descoyunta, si es que puede decirse así, la realidad; trastorna por completo la imagen aparente que tenemos de su estructura y de su dinámica, precisamente para mejor mostrarnos cómo son, cómo es la realidad [...] Sin embargo, creemos ver en este «descoyuntamiento» de la realidad una finalidad muy semejante a la que Brecht buscaba con su idea del «distanciamiento». Para Brecht, la idea del «distanciamiento» se fundamenta en la necesidad de que el espectador tome conciencia de su propia realidad; y a tal fin no presenta la realidad de una manera naturalista, sino que presenta los problemas de esa realidad trasladándolos en el espacio y en el tiempo. Mediante temas distantes e insólitos que deben provocar en el espectador una fuerte sorpresa. La consecuencia prevista es que el espectador relacione ese mundo insólito y sorprendente que ha visto en el escenario con su propia realidad cotidiana, reparando así en cuanto esta tiene de insólita, para este modo, tomar conciencia de esa realidad. El fin último que propone Brecht es la desalienación. En los esperpentos, el método es más elaborado y más directo; la finalidad muy semejante. Valle presenta en el escenario la realidad que vive el espectador, pero de tal manera deformada que este no pueda menos que quedar atónito, pues esta realidad es increíble. Esta imagen esperpéntica de la realidad nos obliga a una toma de conciencia: la conciencia de que vivimos una realidad esperpéntica, la conciencia de que son grotescos unos valores generales en que se fundamenta la realidad concreta que nos rodea. (ARLANDIS, 2016, p. 202).

Realidad. ¿Y qué realidad es esa? España era gobernada en esa época (1923 1930) por Primo de Rivera quien encabezaba una dictadura militar. Esa situación antecedió a la guerra civil y al Franquismo que perduraría en el país hasta los años 70 del siglo XX. En toda la obra -incluidos introducción y epílogo-, sobrevuela la Eutomia, Recife, 22(1): 152-157, Dez. 2018 
presencia militar en España. En algún pasaje se menciona la campaña de Marruecos; los códigos del ejército como dice Friolera -y yo transcribo en el acápite- se imponen a la sociedad; se deja entrever alguna connivencia entre los uniformados y delitos como el contrabando. Y finalmente, en el prólogo dos intelectuales vascos que citan a Don Quijote aluden directamente a Primo de Rivera diciendo uno de sus apellidos: Orbaneja. Dicho Orbaneja era un pintor tan malo que de él dice el Caballero Andante: "Tal vez pintaba un gallo de tal suerte y tan mal parecido, que era menester que con letras góticas escribiese junto a él: «Este es gallo»" (CERVANTES SAAVEDRA, 2015, p. 571)

Así critica Valle sin ambages a un gobierno chapucero e improvisado que mantiene a España en un atraso casi medieval.

Estructura y lenguaje. El texto en sí, dividido en tres partes, contiene su propia proyección de sombras. En la primera los dos intelectuales ya mencionados discuten sobre el arte y su sentido en cuanto contemplan en un teatro de muñecos un adelanto más tosco de lo que veremos en la segunda parte. Ella consiste en el desarrollo en diez escenas del drama en sí. Es curioso ver aquí como en las descripciones de los escenarios Valle coloca detalles dificilísimos de reproducir en el escenario: es como si la obra hubiera sido escrita más para ser leída que representada. Veamos algunos ejemplos: así se describe el fondo de la primera escena:

San Fernando de Cabo Estrivel: Una ciudad empingorotada sobre cantiles. En los cristales de los miradores, el sol enciende los mismos cabrilleos que en la turquesa del mar. A lo largo de los muelles, un mecerse de arboladuras, velámenes y chimeneas. En la punta, estremecida por bocanas de aire, la garita del Resguardo. Olor de caña quemada. Olor de tabaco. Olor de brea. Levante fresco. El himno inglés en las remotas cornetas de un barco de guerra... (VALLE INCLÁN, 1925, p. 41).

Cada una de las escenas se inicia con una descripción por el estilo, esto sin contar con la de los personajes: Friolera es un teniente militar muy viejo y sucio; su mujer, Loreta, exageradamente curvilínea; el amante, "cuarentón, cojo y narigudo"; la beata del pueblo y gestora del drama parece una raposa; los tres militares que deciden la suerte del victimario recuerdan a gatos y ranas... Es decir, desde los escenarios a los 
personajes, todo parece exagerado, deforme, fantochesco. El lenguaje utilizado por el autor refuerza esta idea: A la amante Valle la llama "tarasca"; a la beata, Friolera la acusa de "cotillona"; varias veces la palabra "inverosímil" sustituye a "indiferente" y el lector atento podrá encontrar muchos ejemplos más jugosos.

Optar por la Sangre. Friolera se ve empujado a matar a su mujer pues el ejército no admite cabrones en sus filas y recompensa al que entre ellos lave su honor con sangre. Así lo explica él mismo en el monólogo que reproduzco en más arriba. Sin embargo, Valle muestra que ese camino salvaje solo perdura en España pues en Europa otros aires soplan. Como se describe en la escena séptima, en el diálogo entre Ballarocas y el protagonista, en el billar de Calixta:

Ballarocas- Hay que ser filósofo. Friolera- ¡Pues yo no lo soy! B-¡Mal hecho! En España vivimos muy atrasados. No se inculca la filosofía en los matrimonios, como se hace en otros países. F- ¿Te refieres a la ley del divorcio? B- ¡Ya nos hemos entendido! (VALLE INCLÁN, 1925, p. 162.)

Pero Friolera, sin pruebas ciertas de haber sido traicionado, elegirá el camino de la sangre y terminará matando a su hija. En lugar de lavar su honor será encarcelado, luego de confesar el crimen borracho ante un coronel y su esposa querendona.

El drama central proyecta su sombra sobre el epílogo: un ciego recita la historia que acabamos de presenciar con el final cambiado. El matador es honrado por el Rey y su retrato aparece en las Revistas llustradas. Los dos intelectuales vascos, Don Estrafalario y Don Manolito, escuchan este recitado desde la cárcel "por sospechosos de poner bombas, y de haber hecho mal de ojo a un burro en la Alpujarra" (VALLE INCLÁN, 1925, p. 261.).

De nuevo una alusión al gobierno de Primo de Rivera, quien atacó los regionalismos autonómicos y creó leyes antiseparatistas.

En resumen, Valle mediante un juego de espejos caricaturiza la realidad de España de los años veinte del siglo pasado sin olvidar ningún elemento importante: los militares y su concepto del honor, la guerra de Marruecos, los separatismos reprimidos y el atraso con respecto a otros países europeos. 
Conclusión. ¿Y qué novedad presentan Los cuernos de Don Friolera para el lector del siglo XXI imbuido en la realidad de lo políticamente correcto? Los mismos dramas con un atraso de cien años: Democracias en duda, ejércitos fuertes, la violencia a la orden del día y los crímenes contra la mujer transformados en pandemia en varios países occidentales.

Mientras esto escribo, escucho por la radio que un hombre ha rociado a su mujer con gasolina y la ha prendido fuego...

\section{Referencias bibliográficas}

ARLANDIS, Sergio. Reversos y crisis del código del honor barroco: hacia el esperpento de Valle-Inclán. Monteagudo n. 21, p. 193-210, 2016.

CERVANTES, Miguel de . Don Quijote de la Mancha. Edición Conmemorativa del IV Centenario. Madrid: Alfaguara, 2015.

VALLE INCLÁN, Ramón María del. Los cuernos de Don Friolera. Madrid: Renacimiento, 1925 .

i Docente de portugués en el Centro de Lenguas Extranjeras de la Administración Nacional de Educación Pública de Uruguay (ANEP). Es traductor autónomo portugués-español y autor de varias traducciones de obras literarias del portugués al español.

roman.garciamorales@gmail.com 